\title{
Anatomical etiology of "pseudo-sciatica" from superior cluneal nerve entrapment: a laboratory investigation
}

\author{
This article was published in the following Dove Press journal: \\ Journal of Pain Research \\ I November 2017 \\ Number of times this article has been viewed
}

\author{
Tomoyuki Konno' \\ Yoichi Aota ${ }^{2}$ \\ Hiroshi Kuniya' \\ Tomoyuki Saito' \\ Ning $\mathrm{Qu}^{3}$ \\ Shogo Hayashi ${ }^{3}$ \\ Shinichi Kawata ${ }^{3}$ \\ Masahiro Itoh ${ }^{3}$ \\ 'Department of Orthopaedic \\ Surgery, Yokohama City University \\ Graduate School of Medicine, \\ ${ }^{2}$ Department of Spine \& Spinal Cord \\ Surgery, Yokohama Brain and Spine \\ Center, Yokohama, ${ }^{3}$ Department of \\ Anatomy, Tokyo Medical University, \\ Tokyo, Japan
}

Objective: The superior cluneal nerve ( $\mathrm{SCN}$ ) may become entrapped where it pierces the thoracolumbar fascia over the iliac crest; this can cause low back pain (LBP) and referred pain radiating into the posterior thigh, calf, and occasionally the foot, producing the condition known as "pseudo-sciatica." Because the SCN was thought to be a cutaneous branch of the lumbar dorsal rami, originating from the dorsal roots of L1-L3, previous anatomical studies failed to explain why SCN causes "pseudo-sciatica". The purpose of the present anatomical study was to better elucidate the anatomy and improve the understanding of "pseudo-sciatica" from SCN entrapment. Materials and methods: $\mathrm{SCN}$ branches were dissected from their origin to termination in subcutaneous tissue in 16 cadavers ( 5 male and 11 female) with a mean death age of 88 years (range 81-101 years). Special attention was paid to identify SCNs from their emergence from nerve roots and passage through the fascial attachment to the iliac crest.

Results: Eighty-one SCN branches were identified originating from T12 to L5 nerve roots with 13 branches passing through the osteofibrous tunnel. These 13 branches originated from L3 (two sides), L4 (six sides), and L5 (five sides). Ten of the 13 branches showed macroscopic entrapment in the tunnel.

Conclusion: The majority of SCNs at risk of nerve entrapment originated from the lower lumbar nerve. These anatomical results may explain why patients with SCN entrapment often evince leg pain or tingling that mimics sciatica.

Keywords: superior cluneal nerve, entrapment neuropathy, dorsal rami, pseudo-sciatica, osteofibrous tunnel, LBP

\section{Introduction}

Low back pain (LBP) is a common condition with a life-time prevalence affecting up to $84 \%$ of the population. ${ }^{1-3}$ Chronic LBP is less prevalent, occurring in about $23 \%{ }^{4}$ Large epidemiological studies have shown that up to $37 \%$ of patients with chronic back pain have a neuropathic pain component, ${ }^{5}$ mainly presenting as radicular leg pain. ${ }^{67}$

There are several anatomical ${ }^{8,9}$ and clinical $^{10-15}$ studies describing that entrapment of the superior cluneal nerve (SCN) produces LBP. The SCN is a cutaneous branch of the lumbar dorsal rami that penetrates the psoas major and paraspinal muscles. It traverses through the superficial layer of thoracolumbar fascia before crossing the posterior iliac crest or through the gluteal fascia after crossing the iliac crest and supplies the skin overlying the upper half of the gluteus muscles. ${ }^{8,16,17}$ When the medial SCN branch penetrates the gluteal fascia, the nerve may become entrapped in the space
Department of Spine \& Spinal Cord Surgery, Yokohama Brain and Spine Center, Takigashira I-2-I, Isogo-ku, Yokohama City 235-0012, Kanagawa Prefecture, Japan

Tel $+8 I 457532500$

Fax +81457532859

Email yaota@yokohama-cu.ac.jp 
surrounded by the iliac crest and the fascia attached to the iliac crest, the so called "osteofibrous tunnel."»,13

Entrapment of the SCN is not rare and may cause LBP, often with referred pain in various areas of the leg. ${ }^{11,12,18,19}$ Decades ago, Strong and Davila surgically treated 30 patients by deafferentation of the SCN. ${ }^{14}$ Their patients complained of leg symptoms in areas ranging from the groin to the sole of the foot. In a more recent prospective study, Kuniya et al reported that $\sim 50 \%$ of SCN disorder patients had such leg symptoms. ${ }^{11,12}$ This proportion was $89 \%$ in the 19 cases that required surgery to alleviate severe symptoms. Ten of these surgical patients reported that leg symptoms were more severe than the LBP. Furthermore, eight had a past history of unnecessary lumbar spine surgery, indicating that pain in the lateral calf or foot might contribute to misdiagnosis as a lumbo-sacral disorder. ${ }^{11,12}$ Trescot also mentioned that entrapment of the SCN caused referred pain down the leg, potentially all the way to the foot, and that this pseudo-sciatica clinically mimicked radiculopathy due to lumbar disc herniation or lumbar spinal canal stenosis. ${ }^{19}$

The sciatic nerve is formed by the fourth and fifth lumbar nerve roots and the first two sacral nerve roots. Sciatic pain usually radiates along a broad line from the middle or lower buttock, proceeding dorsolaterally in the thigh due to compression of the L5 nerve root and posteriorly with compression of a1. With less frequent L4 compression, the pain is anterolateral in the thigh. ${ }^{20}$ Earlier anatomical studies ${ }^{16,21,22}$ revealed that the medial branch of the $\mathrm{SCN}$ is composed of the lateral branch of posterior rami of L1, L2, or L3, thus referred pain would appear in the groin or anterior thigh. Therefore, these previous studies do not explain how SCN entrapment causes pseudo-sciatica. To address this issue, the study presented here focuses on the origin of SCNs passing through the osteofibrous tunnel.

\section{Methods}

Bilateral branches of the SCN were observed macroscopically in 5 male and 11 female formalin-preserved cadavers with a total of 23 sides and a mean death age of 88 years (81-101 years). Branches of the SCN were identified where they pierced the dorsal layer of the thoracolumbar fascia or where they passed between the ventral and dorsal layers of the fascia just above the iliac crests. Branches of the SCN were dissected proximally to the intervertebral foramen to identify their point of emergence from nerve roots and distally to the point where they disappeared into the subcutaneous tissue of the buttock. The number of SCN branches was counted where they pass over the iliac crest. Each nerve root was identified in relation to lumbosacral junction and/or the 12th rib (Figures 1 and 2). SCN branches were classified as penetrating the superficial layer of thoracolumbar fascia before crossing the posterior iliac crest or passing through the gluteal fascia after crossing the iliac crest. Penetrating the fascia below the iliac crest is defined as passing through
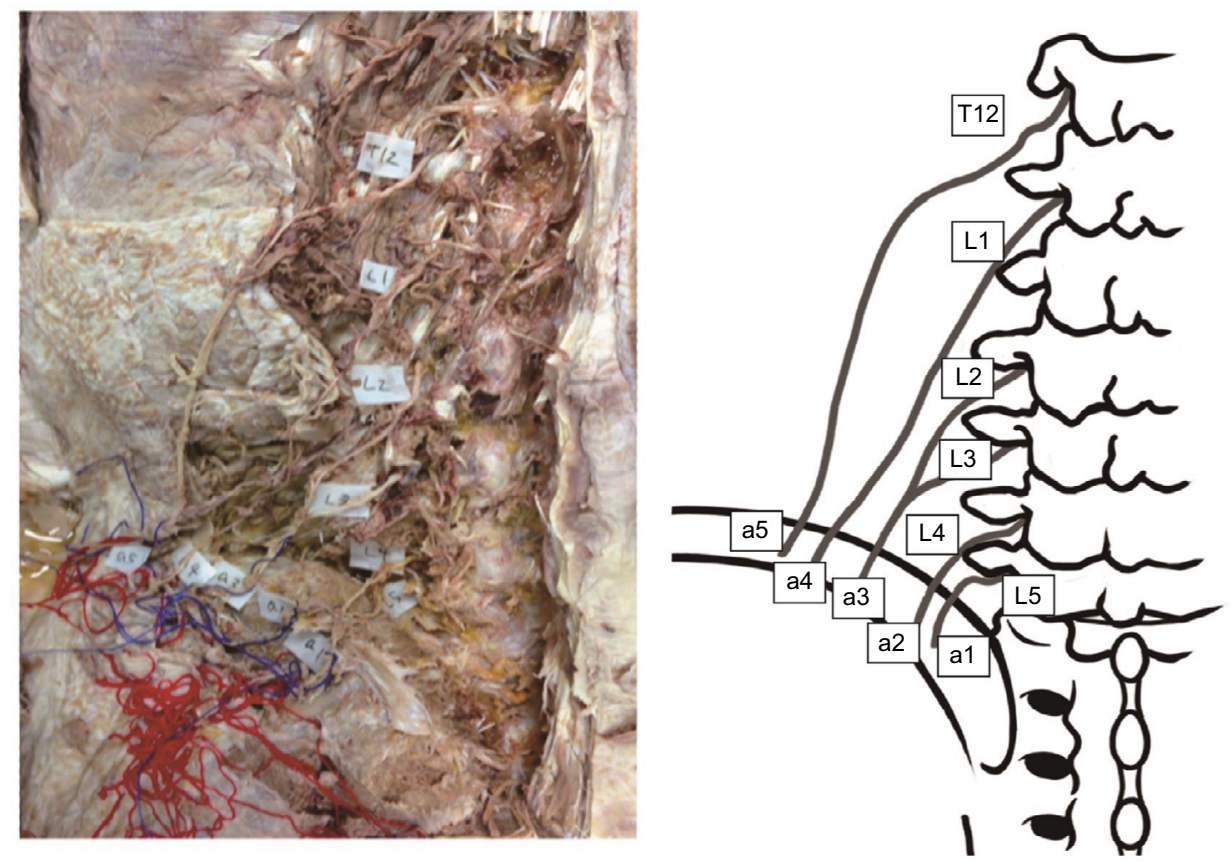

Figure I Photograph and the corresponding illustration showing five branches of the SCN on the left side of a specimen obtained from the cadaver of a 90 -year-old woman (specimen no. 8). The most lateral branch (a5) had separate origins from the TI2 and L2 nerve roots. The third most medial branch (a3) had separate origins from the L2 and $\mathrm{L} 3$ nerve roots.

Abbreviation: SCN, superior cluneal nerve. 

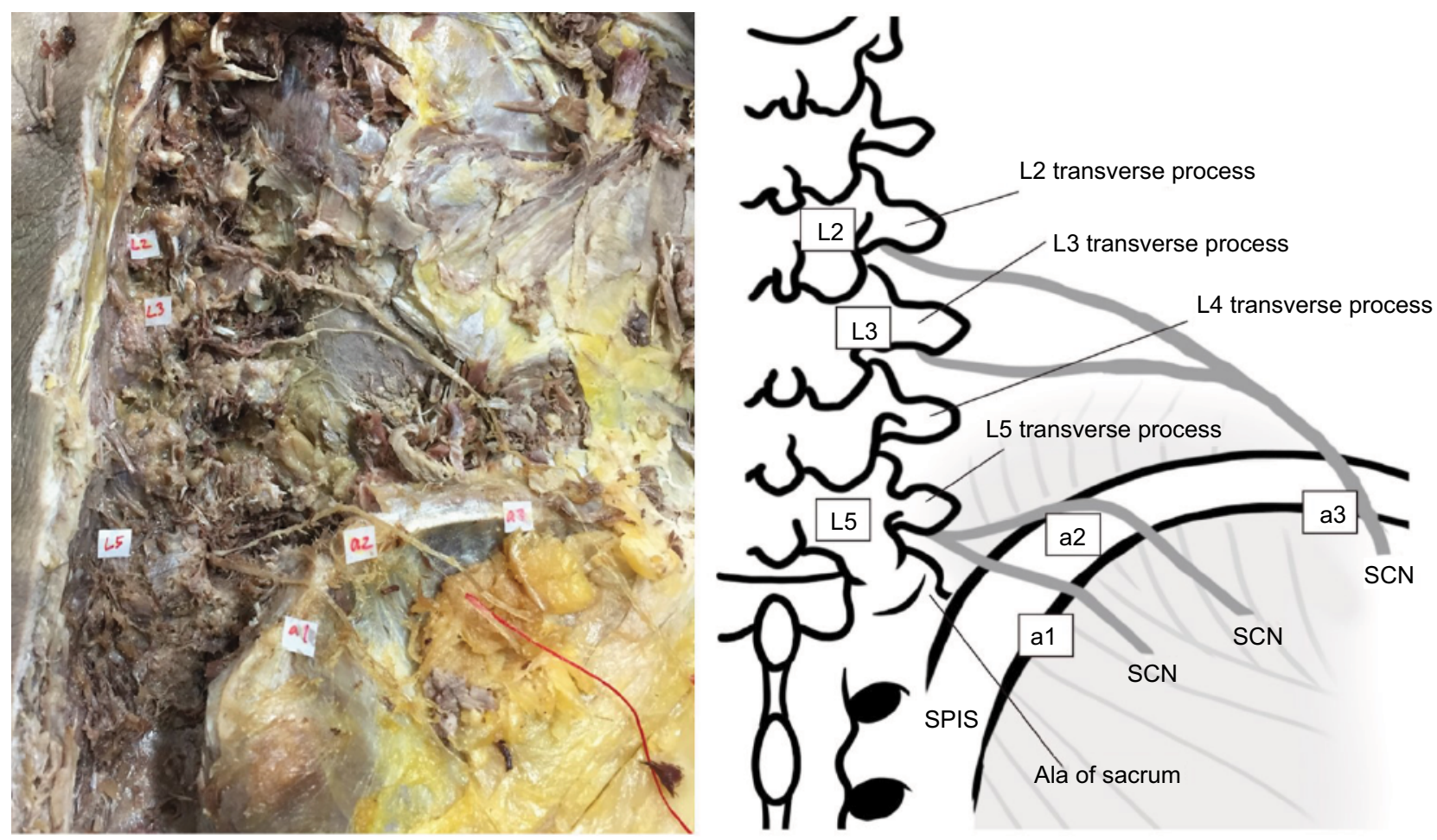

Figure 2 Photographs and the corresponding illustration showing three branches of the SCN on the right side of a cadaveric specimen obtained from an 89-year-old man (specimen no. 22). The L5 nerve roots had a dorsal branch ramifying into the most medial SCN branch (al) and the second most medial branch (a2). The lateral branch of the $\operatorname{SCN}(\mathrm{a} 3)$ had separate origins from the $L 2$ and $L 3$ nerve roots.

Abbreviation: SCN, superior cluneal nerve.

the osteofibrous tunnel. Particular attention was paid to the observation of a constriction of the SCN branch in the osteofibrous tunnel. Linear distances from the midline and the posterior superior iliac spine (PSIS) to the SCN branches over the iliac crest were measured using a digital caliper (Mitsutoyo Corp., Kawasaki, Japan).

This anatomical study was approved by the Institutional Ethics Committee of our institution (Tokyo Medical University No. 2843). Cadaveric donors designated for education or research participated in this study.

\section{Results}

A total of $81 \mathrm{SCN}$ branches were identified on the 23 examined sides. Numbers of SCN branches as they crossed the iliac crest in each specimen were three (15 sides), four (four sides), and five (four sides). Levels of nerve roots originating SCN branches are shown in Table 1. Of the 81 SCN branches, four branches had a separate origin from multiple nerve roots, three from two nerve roots (specimen no. 8 and 22), and one from three nerve roots (specimen no. 17) (Figures 1 and 2). Six nerve roots had dorsal branches ramifying into multiple SCN branches (specimen no. 6-8, 11, 17, and 22) (Figure 2). The most medial branch of the SCN originated from L3 (two sides), L4 (10 sides), L5 (10 sides), and one branch had separate origins from L2, L3, and L4 nerve roots. In one specimen, the most medial SCN branch anastomosed with the middle cluneal nerve in the mid-buttock subcutaneous tissue. The second most medial branch of the SCN originated from L1 (one side), L2 (two sides), L3 (nine sides), L4 (nine sides), and L5 (two sides).

Thirteen of the $81 \mathrm{SCN}$ branches passed through the osteofibrous tunnel. Seven sides (specimen no. 3, 10, 11, 13, 14, 21, and 23) had one SCN branch and three sides (specimen no. 6-8) had two SCN branches passing through the osteofibrous tunnel. These 13 branches originated from L3 (two sides), L4 (six sides), and L5 (five sides). Of these, nine were the most medial branches originating from L4 (four branches) and L5 (five branches), three were the second most medial branches from L3 (one branch) and L4 (two branches), and one was the third most medial branch from L3.

Ten of the 13 branches passing through the osteofibrous tunnel had obvious entrapment (Figure 3). Of these 10 branches entrapped in the tunnel, seven nerves were the most medial branch originating from L4 (three branches) and L5 (four branches), two were the second most medial branch from L3 (one side) and L4 (one side), and one was the third most medial branch from L3.

Distances from the midline and the PSIS to the branches of the SCN crossing over the iliac crest, and the diameters 

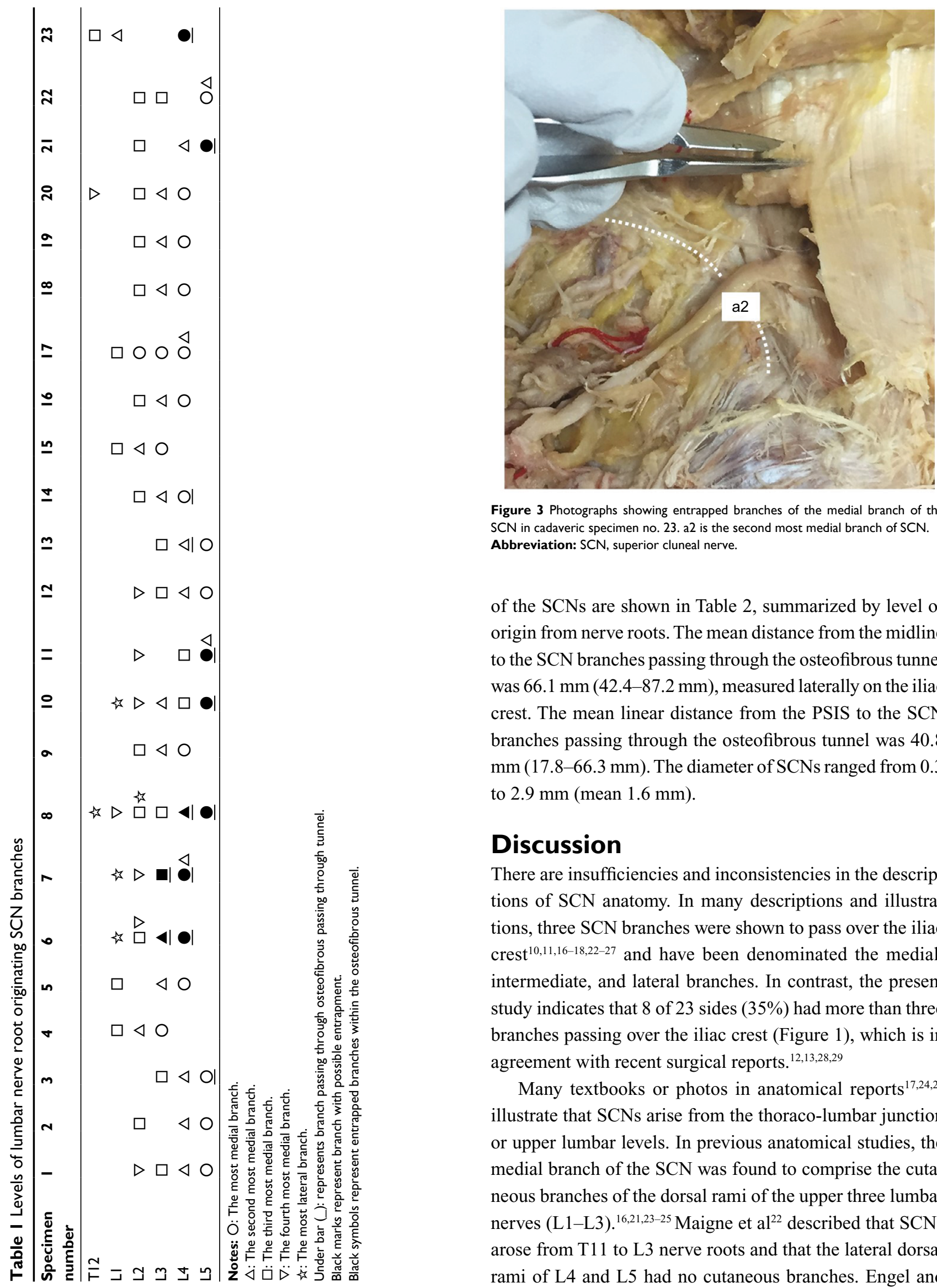

Figure 3 Photographs showing entrapped branches of the medial branch of the SCN in cadaveric specimen no. 23. a2 is the second most medial branch of SCN. Abbreviation: SCN, superior cluneal nerve.

of the SCNs are shown in Table 2, summarized by level of origin from nerve roots. The mean distance from the midline to the SCN branches passing through the osteofibrous tunnel was $66.1 \mathrm{~mm}(42.4-87.2 \mathrm{~mm})$, measured laterally on the iliac crest. The mean linear distance from the PSIS to the SCN branches passing through the osteofibrous tunnel was 40.8 $\mathrm{mm}(17.8-66.3 \mathrm{~mm})$. The diameter of SCNs ranged from 0.3 to $2.9 \mathrm{~mm}$ (mean $1.6 \mathrm{~mm}$ ).

\section{Discussion}

There are insufficiencies and inconsistencies in the descriptions of SCN anatomy. In many descriptions and illustrations, three SCN branches were shown to pass over the iliac crest $^{10,11,16-18,22-27}$ and have been denominated the medial, intermediate, and lateral branches. In contrast, the present study indicates that 8 of 23 sides (35\%) had more than three branches passing over the iliac crest (Figure 1), which is in agreement with recent surgical reports. . $^{12,13,28,29}$

Many textbooks or photos in anatomical reports ${ }^{17,24,25}$ illustrate that SCNs arise from the thoraco-lumbar junction or upper lumbar levels. In previous anatomical studies, the medial branch of the SCN was found to comprise the cutaneous branches of the dorsal rami of the upper three lumbar nerves (L1-L3). ${ }^{16,21,23-25}$ Maigne et $\mathrm{al}^{22}$ described that SCNs arose from $\mathrm{T} 11$ to $\mathrm{L} 3$ nerve roots and that the lateral dorsal rami of L4 and L5 had no cutaneous branches. Engel and 
Table 2 Distances from anatomical landmarks and diameter of superior cluneal nerves

\begin{tabular}{llll}
\hline $\begin{array}{l}\text { Specimen } \\
\text { number }\end{array}$ & $\begin{array}{l}\text { Distance from midline } \\
\text { (mean } \pm \text { SD), } \mathbf{~ m m}\end{array}$ & $\begin{array}{l}\text { Distance from PSIS } \\
\text { (mean } \pm \text { SD), } \mathbf{~ m m}\end{array}$ & $\begin{array}{l}\text { Diameter of SCN } \\
\text { (mean } \pm \text { SD), } \mathbf{m m}\end{array}$ \\
\hline TI2 & $91.5 \pm 4.8$ & $66.0 \pm 13.4$ & $1.5 \pm 1.0$ \\
LI & $90.1 \pm 14.5$ & $60.6 \pm 16.5$ & $1.3 \pm 0.6$ \\
L2 & $78.8 \pm 13.4$ & $50.7 \pm 9.9$ & $1.5 \pm 0.4$ \\
L3 & $71.5 \pm 13.9$ & $42.9 \pm 11.4$ & $1.5 \pm 0.3$ \\
L4 & $66.7 \pm 13.9$ & $42.6 \pm 10.1$ & $1.6 \pm 0.6$ \\
L5 & $62.4 \pm 22.2$ & $40.8 \pm 18.1$ & $1.8 \pm 0.5$ \\
\hline
\end{tabular}

Abbreviations: SCN, superior cluneal nerve; PSIS, posterior superior iliac spine.

Bogduk $^{30}$ studied the lumbar dorsal rami and found that the L1-L3 lateral branches pierced the thoracolumbar fascia and became cutaneous, whereas the L4 lateral branch remained entirely intramuscular and no lateral branch arose from L5. Aizawa and Kumaki ${ }^{23}$ described SCNs originating from dorsal roots of $\mathrm{T} 12$ to L4. In contrast, our study found SCNs arising from $\mathrm{T} 12$ to $\mathrm{L} 5$ nerve roots.

It was formerly believed that all branches of the SCN pierce the thoracolumbar fascia above the iliac crest ${ }^{11,19,23,31-35}$ until Maigne et al found entrapment of the most medial branch in the osteofibrous tunnel. Subsequent cadaveric dissections by Maigne et al, ${ }^{22} \mathrm{Lu}$ et al, ${ }^{27}$ and $\mathrm{Xu}$ et $\mathrm{al}^{36}$ determined that the medial SCN branch consistently passes through the osteofibrous tunnel while the intermediate and lateral branches never pass through the osteofibrous tunnel. ${ }^{11,22,27,34}$ Agur $^{24}$ found that $80 \%$ of the medial branches passed through the osteofibrous tunnel, while Yazaki et $\mathrm{a}^{29}$ reported this number to be $95 \%$. Kuniya et $\mathrm{al}^{8}$ dissected 59 cadavers and found $56 \%$ to have at least one branch running through an osteofibrous tunnel; $36 \%$ had one branch, $17 \%$ had two branches, and $3 \%$ had three branches in the osteofibrous tunnel. In our study, 30\% (7/23) had one SCN branch and 13\% (3/23) had two SCN branches passing through the osteofibrous tunnel. Nine of 13 $\mathrm{SCN}$ branches passing through the osteofibrous tunnel were the most medial branch, three were the second most medial branch, and one was the third most medial branch.

Maigne et $\mathrm{al}^{22}$ reported that the SCNs passing through the osteofibrous tunnel arose from L1 nerve roots in $60 \%$, L2 in $27 \%$, and $\mathrm{L} 3$ in $13 \%$. In the present study, we found SCN branches passing through the osteofibrous tunnel originated from L3 to L5 nerve roots.

Several investigations found the SCN passing 70-80 $\mathrm{mm}$ laterally over the iliac crest. ${ }^{18,22}$ Our results determined that the average distance from midline to the SCNs passing through the osteofibrous tunnel was $66.1 \mathrm{~mm}$ (42.4-87.2 $\mathrm{mm}$ ) and that the mean linear distance from the PSIS to the $\mathrm{SCN}$ was $40.8 \mathrm{~mm}$.
The differences between previous reports and our study may arise from differing purposes of the studies. Previous studies were intended to define the lateral cutaneous branches innervation of the lower back ${ }^{22}$ or how to alleviate pain at the iliac crest following bone harvest. ${ }^{16}$ While seeking the cutaneous innervation of the lower back, Maigne et $\mathrm{al}^{22}$ unexpectedly found entrapment of the most medial branch of the SCN in the osteofibrous tunnel in two of 37 dissections. In their report, these authors observed tiny medial branches crossing the crest that were impossible to trace. In contrast, our aim was specifically to identify SCNs at risk of entrapment and their origin from nerve roots. In addition, our observations were done with the knowledge that there are several anatomical variations in the running course of the SCN branches and that multiple branches may pass through the osteofibrous tunnel. ${ }^{8,28}$ We were also careful to preserve the thin branches and anastomoses passing through the osteofibrous tunnel.

In addition, the proportion of constriction of the $\mathrm{SCN}$ in the osteofibrous tunnel, $30 \%$ or $7 / 23$ specimens, in our study differs considerably from that of previous studies. Maigne et al reported that $5 \%$, or $2 / 37$, of his cadavers showed marked compression of the medial branches of the SCN in the osteofibrous tunnel. ${ }^{22}$ Kuniya et al observed severe constriction of the $\mathrm{SCN}$ in the bony groove covered by the fascial attachment of the gluteus muscle to the iliac crest in only two out of 109 specimens. ${ }^{8}$ Because true constriction is rare and repetitive friction between the $\mathrm{SCN}$ and fascia, even without direct compression by the ilium, can cause severe symptoms, ${ }^{12,28}$ we included moderate constriction of the SCN in the osteofibrous tunnel in our results.

\section{Conclusion}

We have identified more extensive spinal nerve origins of SCNs ranging from $\mathrm{T} 12$ to $\mathrm{L} 5$. We indicated that predominantly the L4 and L5 lateral branches run through the osteofibrous tunnel in the fascia overlying the iliac crest. This evidence can explain how SCN entrapment disorder 
causes various leg symptoms mimicking sciatica. Our study provides an anatomical assessment of SCN entrapment in the osteofibrous tunnel and a mechanism whereby this causes the leg symptoms of pseudo-sciatica.

\section{Author contributions}

Author contributions to the study and manuscript preparation are as follows: YA contributed to drafting the manuscript; TK performed data analysis; all authors contributed toward data analysis, drafting and revising the paper and agree to be accountable for all aspects of the work.

\section{Disclosure}

The authors report no conflicts of interest in this work.

\section{References}

1. Andersson GB. Epidemiological features of chronic low-back pain. Lancet. 1999;354(9178):581-585.

2. Deyo RA, Weinstein JN. Low back pain. $N$ Engl J Medicine. 2001; 344(5):363-370.

3. Balague F, Mannion AF, Pellise F, Cedraschi C. Non-specific low back pain. Lancet. 2012;379(9814):482-491.

4. Fernyhough JC, Schimandle JJ, Weigel MC, Edwards CC, Levine AM. Chronic donor site pain complicating bone graft harvesting from the posterior iliac crest for spinal fusion. Spine. 1992;17(12):1474-1480.

5. Freynhagen R, Baron R, Gockel U, Tolle TR. painDETECT: a new screening questionnaire to identify neuropathic components in patients with back pain. Curr Med Res Opin. 2006;22(10):1911-1920.

6. Schmidt CO, Schweikert B, Wenig CM, et al. Modelling the prevalence and cost of back pain with neuropathic components in the general population. Eur J Pain. 2009;13(10):1030-1035.

7. Tarulli AW, Raynor EM. Lumbosacral radiculopathy. Neurol Clin. 2007;25(2):387-405.

8. Kuniya H, Aota Y, Saito T, et al. Anatomical study of superior cluneal nerve entrapment. J Neurosurg Spine. 2013;19(1):76-80.

9. Sittitavornwong S, Falconer DS, Shah R, Brown N, Tubbs RS. Anatomic considerations for posterior iliac crest bone procurement. J Oral Maxillofac Surg. 2013;71(10):1777-1788.

10. Berthelot JM, Delecrin J, Maugars Y, Caillon F, Prost A. A potentially underrecognized and treatable cause of chronic back pain: entrapment neuropathy of the cluneal nerves. J Rheumatol. 1996;23(12): 2179-2181.

11. Kuniya H, Aota Y, Nakamura N, Kawai T, Tanabe H, Saito T. Low back pain patients with suspected entrapment of the superior cluneal nerve. J Spine Res. 2011;2(6):1032-1035. Japanese.

12. Kuniya H, Aota Y, Kawai T, Kaneko K, Konno T, Saito T. Prospective study of superior cluneal nerve disorder as a potential cause of low back pain and leg symptoms. J Orthop Surg Res. 2014;9:139.

13. Maigne JY, Doursounian L. Entrapment neuropathy of the medial superior cluneal nerve. Nineteen cases surgically treated, with a minimum of 2 years' follow-up. Spine. 1997;22(10):1156-1159.
14. Strong EK, Davila JC. The cluneal nerve syndrome; a distinct type of low back pain. Ind Med Surg. 1957;26(9):417-429.

15. Talu GK, Ozyalcin S, Talu U. Superior cluneal nerve entrapment. Reg Anesth Pain Med. 2000;25(6):648-650.

16. Tubbs RS, Levin MR, Loukas M, Potts EA, Cohen-Gadol AA. Anatomy and landmarks for the superior and middle cluneal nerves: application to posterior iliac crest harvest and entrapment syndromes. J Neurosurg Spine. 2010;13(3):356-359.

17. Skandalakis JE. Essentials of human anatomy. JAMA. 1995;273(4): 352-353.

18. Aota Y, Kuniya H, Konno T, Kawai T, Saito T. Cluneal nerve: [Entrapment of the superior/middle cluneal nerves can cause leg pain and/or tingling, and may mimick lumbo-sacral spinal disorders.] J Spine Res. 2014;5(6):951-955. Japanese.

19. Trescot AM. Cryoanalgesia in interventional pain management. Pain Phys. 2003;6(3):345-360.

20. RopperAH,Zafonte RD. Sciatica. NEnglJMed.2015;372(13):1240-1248.

21. Netter FH. Atlas of Human Anatomy. Philadelphia, PA: Elsevier Health Sciences; 2010.

22. Maigne JY, Lazareth JP, Guerin Surville H, Maigne R. The lateral cutaneous branches of the dorsal rami of the thoraco-lumbar junction. An anatomical study on 37 dissections. Surg Radiol Anatomy. 1989;11(4):289-293.

23. Aizawa Y, Kumaki K. [The courses and the segmental origins of the cutaneous branches of the thoracic dorsal rami]. Kaibogaku Zasshi. 1996;71(3):195-210. Japanese.

24. Agur AM, Dalley AF. Grant's Atlas of Anatomy. Philadelphia, PA: Lippincott Williams \& Wilkins; 2009.

25. Standring S, Ellis H, Healy J, et al. Gray's anatomy: the anatomical basis of clinical practice. Am J Neuroradiol. 2005;26(10):2703.

26. Bogduk N, Long DM. The anatomy of the so-called "articular nerves" and their relationship to facet denervation in the treatment of low-back pain. J Neurosurg. 1979;51(2):172-177.

27. Lu J, Ebraheim NA, Huntoon M, Heck BE, Yeasting RA. Anatomic considerations of superior cluneal nerve at posterior iliac crest region. Clin Orthop Relat Res. 1998(347):224-228.

28. Aota Y. Entrapment of middle cluneal nerves as an unknown cause of low back pain. World J Orthop. 2016;7(3):167-170.

29. Yazaki S, Ohwaki Y, Urata S, Watanabe K. [Chronic posterior iliac crest donor site pain and anatomic considerations for superior cluneal nerves.] Seikei Geka. 1997;48(4):397-403. Japanese.

30. Engel R, Bogduk N. The menisci of the lumbar zygapophysial joints. J Anatomy. 1982;135(Pt 4):795-809.

31. Asano S, Kaneda K. [Cause and management of donor site pain after harvesting autologous iliac bone grafts.] Sekitsui Sekizui. 1993;6(3):191-195. Japanese.

32. Banwart JC, Asher MA, Hassanein RS. Iliac crest bone graft harvest donor site morbidity. A statistical evaluation. Spine. 1995;20(9):1055-1060.

33. Kurz LT, Garfin SR, Booth RE Jr. Harvesting autogenous iliac bone grafts. A review of complications and techniques. Spine. 1989;14(12): 1324-1331.

34. Hutchinson MR, Dall BE. Midline fascial splitting approach to the iliac crest for bone graft. A new approach. Spine. 1994;19(1):62-66.

35. Mirovsky Y, Neuwirth MG. Comparison between the outer table and intracortical methods of obtaining autogenous bone graft from the iliac crest. Spine. 2000;25(13):1722-1725.

36. Xu R, Ebraheim NA, Yeasting RA, Jackson WT. Anatomic considerations for posterior iliac bone harvesting. Spine. 1996;21(9):1017-1020. 
The Journal of Pain Research is an international, peer reviewed, open access, online journal that welcomes laboratory and clinical findings in the fields of pain research and the prevention and management of pain. Original research, reviews, symposium reports, hypothesis formation and commentaries are all considered for publication
The manuscript management system is completely online and includes a very quick and fair peer-review system, which is all easy to use. Visit http://www.dovepress.com/testimonials.php to read real quotes from published authors. 